\title{
A Case of Facial Pain and Vesicular Rash
}

\author{
Matt Baichi \\ Thomas Jefferson University
}

Follow this and additional works at: https://jdc.jefferson.edu/tmf

Part of the Dermatology Commons

Let us know how access to this document benefits you

\section{Recommended Citation}

Baichi, Matt (2003) "A Case of Facial Pain and Vesicular Rash," The Medicine Forum: Vol. 4 , Article 4. DOI: https://doi.org/10.29046/TMF.004.1.005

Available at: https://jdc.jefferson.edu/tmf/vol4/iss1/4

This Article is brought to you for free and open access by the Jefferson Digital Commons. The Jefferson Digital Commons is a service of Thomas Jefferson University's Center for Teaching and Learning (CTL). The Commons is a showcase for Jefferson books and journals, peer-reviewed scholarly publications, unique historical collections from the University archives, and teaching tools. The Jefferson Digital Commons allows researchers and interested readers anywhere in the world to learn about and keep up to date with Jefferson scholarship. This article has been accepted for inclusion in The Medicine Forum by an authorized administrator of the Jefferson Digital Commons. For more information, please contact: JeffersonDigitalCommons@jefferson.edu. 


\section{A Case of Facial Pain and Vesicular Rash}

Matt Baichi, MD, Resident, Internal Medicine 2000-2003

The patient is an 81 year old male with a past medical history of non-insulin dependent diabetes mellitus, hypertension, and dyslipidemia who presents with a complaint of facial pain. The pain began 3-4 days before presentation to his primary care physician. It was constant and intense. There was no history of similar head or facial pain, visual changes, jaw claudication, rash, tearing, nasal discharge, photophobia, phonophobia, sinus congestion, tooth ache, nor neurologic complaints. There was no relief with over-the-counter analgesics. A rash subsequently developed over his left forehead and scalp. At presentation, vital signs were stable. Skin examination revealed an erythematous vesicular rash over the left forehead. Eye examination revealed pupils equal, round, and reactive to light. Visual fields and acuity were intact. No papilledema was noted on fundoscopic exam. Ear, nose, mouth, and throat were normal. Neurologic examination revealed normal mental status, intact cranial nerves, full strength and sensation, symmetric normal reflexes, and normal gait. Neck, heart, lung, abdomen, and extremity examinations were normal. The patient was diagnosed with herpes zoster. His condition was complicated by chronic pain in the distribution of the original rash.

\section{Discussion}

Herpes zoster (or shingles) is the reactivation of dormant varicella virus. Herpes zoster typically presents as pain and rash. The rash is a unilateral dermatomal eruption that involves thoracic, cervical or ophthalmic regions. It begins as patches of erythema and progresses to grouped vesicles which pustulate and crust in 7-10 days. The pain usually precedes the rash by days to weeks. The rash usually heals in 2-4 weeks, but the pain may persist indefinitely. Pain that persists beyond a defined interval is termed postherpetic neuralgia (PHN).

\section{Definition}

The prevalence of PHN has been blurred by the inconsistency in defining the condition. Some authors define it as any pain persisting after resolution of rash. Others define it as pain persisting for various intervals after rash onset or resolution. A more precise classification has been proposed which includes acute and subacute neuralgia along with postherpetic neuralgia ${ }^{6}$.
Acute herpetic neuralgia is defined as pain occurring during the first thirty days after rash onset. Subacute herpetic neuralgia is defined as pain that resolves within three months after the acute phase. Postherpetic neuralgia is defined as pain which persists beyond four month of rash onset.

\section{Incidence and risk factors}

The incidence of PHN has been estimated by meta analysis review of acyclovir trials in zoster associated chronic pain 7 . Pooled data from the placebo arms of 14 trials (529 patients) revealed a $22 \%$ incidence of PHN (pain at 3-6 months). It has long been known that incidence increases with age ${ }^{8,9}$. A recent prospective study of 421 patients with first episode herpes zoster revealed an overall incidence of $7 \%$ at three months ${ }^{10}$. In patients younger than 60 years, only $2 \%$ had pain at three months, which was mild in all cases. In patients 60 years and older, both the frequency and severity of pain increased. Overall incidence of PHN was 20\% at three months (with $1.7 \%$ being severe) and $10 \%$ at 12 months (all with mild to moderate severity). In addition to age, other risk factors include the severity of acute zoster pain, the severity of the cutaneous manifestations, the severity of sensory dysfunction in the affected dermatome, the presence of a painful prodrome, and fever greater than 38 degrees Celsius ${ }^{6}$.

\section{Treatment}

Two recent reviews summarize the evidence supporting the use of topical lidocaine patch, tricyclic antidepressants, gabapentin, and opioid analgesics in treating postherpetic neuralgia ${ }^{2,5}$.

\section{Lidocaine patch}

In a double-blind controlled study, Rowbotham and colleagues ${ }^{11}$ tested the efficacy of topical 5\% lidocaine patch in 35 patients (average age 75, average duration of pain 48 months) with PHN of the torso or limbs. Patients experienced significant pain relief with topical lidocaine applied for 12 hours/day.

\section{Antidepressants}

Tricyclic antidepressants have long been the cornerstone of PHN treatment. Max ${ }^{12}$ reviews the early evidence 
supporting their use: four placebo-controlled crossover studies using amitriptyline (a blocker of both norepinephrine and serotonin reukptake), showed a response rate of 44-67\%; one study using desipramine (a specific norepinephrine reuptake blocker) showed a response rate of $63 \%$. Side effects of these medicines include dry mouth, urinary retention, constipation, sedation, and orthostatic hypotension.

In a recent double-blind crossover trial comparing nortriptyline with amitriptyline, Watson et $\mathrm{al}^{13}$ found that both drugs had equal efficacy (55-58\%) but nortriptyline had more tolerable side effects. Inclusion criteria required duration of PHN more than 3 months (median 13 months) with pain of at least moderate severity for at least one half of each day. Patients were treated with 5 weeks of one drug followed by a 2 week wash out period followed by 5 weeks of the alternate drug. Each drug was started at $10 \mathrm{mg}$ (if age greater that 65 ) or $20 \mathrm{mg}$ (if age less than 65 ). Dosage was increased by $10 \mathrm{mg}$ every 3-5 days (max dose limit $150 \mathrm{mg}$ /day) until pain relief was adequate or intolerable side effects occurred. If the latter occurred, the dose was reduced and maintained at a tolerable level for the remainder of the trial. The most common side effects (in order of frequency) were dry mouth, constipation, and drowsiness. Of the 31 patients who completed the study, dose limiting side effects were experienced by 5 patients using nortriptyline versus 10 patients using amitryptiline $(\mathrm{p}=0.05)$. The average dose in responders was nortriptyline $75 \mathrm{mg}$ per day and amitriptyline $58 \mathrm{mg}$ per day.

This data supports the use of nortriptyline (dosed as above) as first line antidepressant therapy in PHN with amitriptyline or desipramine as alternate therapies. Desipramine is similarly titrated by starting at 10$20 \mathrm{mg} /$ day with an average tolerated dose of $167 \mathrm{mg} /$ day with a max dose of $250 \mathrm{mg} /$ day (14). Max $^{12}$ points out that the benefit of this drug class can be enhanced by future research focusing on efficacy of SSRI's (serotonin selective reuptake inhibitors), concentration-response studies of the above agents, and drug combination trials.

\section{Anticonvulsants}

In 1998, Rowbotham et $\mathrm{al}^{15}$ conducted a multicenter, randomized, double-blind, placebo-controlled, parallel design, 8 week trial comparing gabapentin to placebo. A total of 229 patients were randomized (gabapentin $n=113$, placebo $\mathrm{n}=116$ ). Patients in the study arm received a starting dose of gabapentin $300 \mathrm{mg}$ per day. The dose was titrated over 4 weeks to $3600 \mathrm{mg} /$ day divided three times daily (regardless of whether efficacy was achieved at a lower dose) or until intolerable side effects occurred. The dose achieved during titration was then maintained for the duration of the study. The primary outcome was average daily pain as determined by a pain scale $(0=$ no pain, $10=$ worst possible pain). Over the 8 week trial, pain improved in the gabapentin group from 6.3 to 4.2 . The placebo group went from 6.5 to 6.0. The major adverse effects in the gabapentin group were somnolence, dizziness, ataxia, peripheral edema, and infection. This study established gabapentin as an additional first line agent in the treatment of postherpetic neuralgia.

\section{Analgesics}

In 1998, Watson and Babul ${ }^{16}$ conducted a single-center, randomized, double-blind, placebo-controlled, 8 week crossover evaluation of oxycodone in patients with postherpetic neuralgia. Thirty eight patients completed the study. Each patient was randomized to receive either oxycodone $10 \mathrm{mg}$ every 12 hours or placebo. The dose was increased at weekly intervals over four weeks (10, 20 , or $30 \mathrm{mg}$ every 12 hours) to the highest tolerated dose (up to a maximum of $60 \mathrm{mg} /$ day). This was followed by 4 weeks of alternate agent with no washout period. Pain was assessed by a daily diary using a visual analog scale and a categorical pain intensity scale. The average oxycodone dose at the end of 4 weeks was $45 \mathrm{mg} /$ day. Patients experienced a statistically significant reduction in pain with oxycodone compared to placebo.

\section{Conclusion}

The above evidence provides a framework for the medical treatment of PHN. Topical lidocaine patch, tricyclic antidepressants (especially nortriptyline), gabapentin, and sustained release oxycodone have proven efficacy in controlled clinical trials. A large number of alternate agents as well as combination therapy with the above 
drugs still need to be evaluated in clinical trials. Finally, patients should receive early referral to pain clinics where a multidisciplinary treatment approach usually includes cognitive-behavioral therapy which has a well established role in other chronic pain syndromes.

\section{Bibliography: posthepetic neuralgia}

1. Kost RG, Strauss SE. Postherpetic neuralgia: pathogenesis, treatment, and prevention. N Engl J Med 1996; 335: 32-42.

2. Kanazi GE, Johnson RW, Dworkin RH. Treatment of postherpetic neuralgia: an update. Drugs 2000; 59: 1113-1126.

3. Watson CPN, editor. Herpes zoster and postherpetic neuralgia. Amsterdam: Elsevier, 2001.

4. Alper BS and Lewis PR. Does treatment of acute herpes zoster prevent or shorten postherpetic neuralgia? J Fam Pract 2000; 49: 255-264.

5. Alper BS and Lewis PR. Treatment of postherpetic neuralgia. J Fam Pract 2000; 51: 121-128.

6. Dworkin RH and Portenoy RK. Pain and its persistence in herpes zoster. Pain 1996; 67: 241-251.

7. Crooks RJ, Jones DA, and Fiddian AP. Zoster -associated chronic pain: an overview of clinical trials with acyclovir. Scand J Infect Dis 1991; Suppl. 78: 62-68.

8. Burgoon CF, Burgoon JS, and Baldridge GD. The natural history of herpes zoster. JAMA 1957; 164: 265-269.
9. DeMoragas JM and Kierland RR. The outcome of patients with herpes zoster. AMA Arch Dermatol 1957; 75: 193-196.

10. Helgason S, Peturson G, Gudmundsson S, and Sigurdsson JA. Prevalence of postherpetic neuralgia after a single episode of herpes zoster: prospective study with long term follow up. BMJ 2000; 321: 1-4.

11. Rowbotham MC, Davies PS, Verkempinck C, and Galer BS. Lidocaine patch: double-blind controlled study of a new treatment method for post-herpetic neuralgia. Pain 1996; 65: 39-44.

12. Max MB. Treatment of post herpetic neuralgia: antidepressants. Ann Neurol 1994; 35 suppl.: s50-53.

13. Watson CPN, Lee V, Chipman M, Reed K. Nortriptyline versus amitriptyline in postherpetic neuralgia: a randomized trial. Neurology 1998; 51: 1166-1171.

14. Kishore-Kumar R, Max MB, Schafer SC, Gaughan AM, Smoller B, Gracely RH, and Dubner R. Desipramine relieves postherpetic neuralgia. Clin Pharmacol Ther 1990; 47: 305-312.

15. Rowbotham M, Harden N, Stacey B, Bernstein P, and Magnus-Miller L. Gabapentin for the treatment of postherpetic neuralgia. JAMA 1998; 280: 1837-1842.

16. Watson CPN and Babul N. Efficacy of oxycodone in neuropathic pain, a randomized trial in postherpetic neuralgia. Neurology 1998; 50: 1837-1841. 